\title{
A PROTECTIVE MASK FOR USE AFTER OPERATIONS ON THE EYE
}

BY

\section{H. KIRKPATRICK}

LONDON

INJURY to the operated eye after a cataract extraction or other intraocular operation is an accident which may cause much anxiety both to the surgeon and to the patient, and I never met with any device to prevent such an occurrence in which I had real confidence until I employed a protective mask made of dental wax.

The mask is made by moulding dental stent on to the plaster cast of a face, the eyes of which are represented by large globular

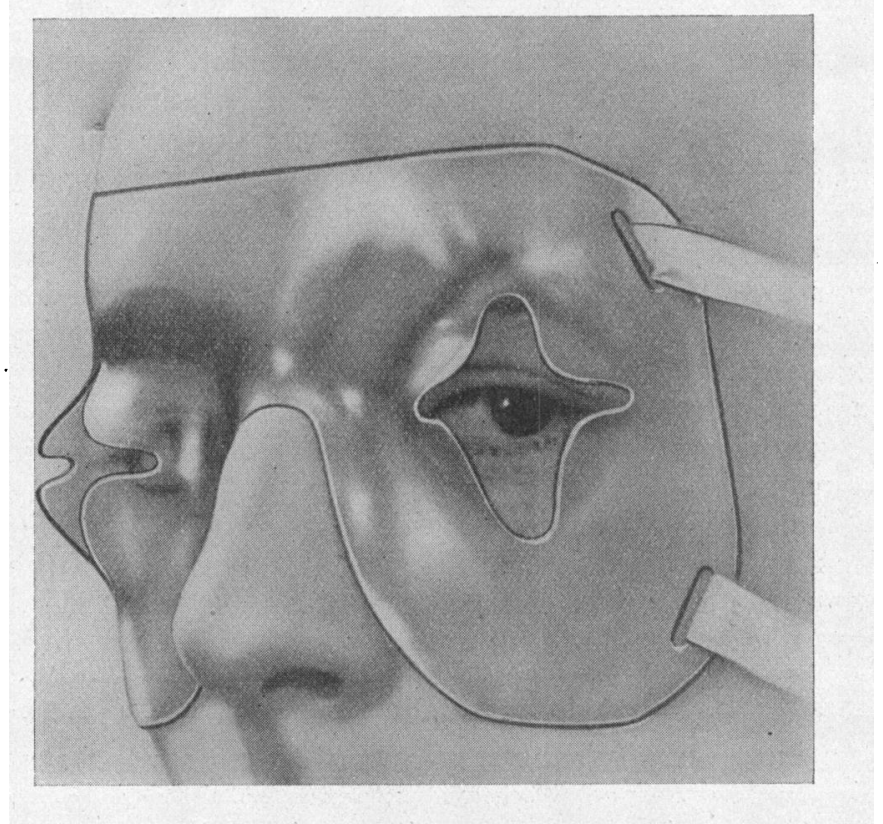

prominences. Care is taken to mould the wax accurately on to the orbital margins, and an aperture is made in the centre of each eye projection. Ventilation holes and holes for the attachment of tapes are pierced with any suitable instrument whilst making the mask.

Previous to an operation the wax shield, in order to make it fit the individual case, is softened in hot water (just pleasantly hot for the hands) and is pressed against the patient's face so 
as to make it comfortably fit his orbital margins. After operation a layer of gamgee, or other dressing, is laid on the closed lids and the mask is applied and used instead of a bandage, being fixed by tapes passed round the head above and below each ear. If preferred a bandage may, of course, be used to fix mask and dressing. One or both eyes can be released at any desired time and the shield will then provide comfortable protection. The mask can be sterilized by immersion in mercury lotion, and it is desirable to have two of them for each patient so that one can be sterilized whilst the other is in use.

A shield for one eye only can be made in the same way. In this case a tongue of the wax is carried from the upper part of the shield on to the superciliary ridge of the other eye.

The plaster mould is made by taking an impression of the orbital margins in plasticine or in modelling clay, either from a person or from a skull. The area over the eyes is pushed out to form the prominences and a cast made in plaster of Paris. The wax I have used is Dresch Impression material. This is supplied in tablets of such a size that each makes a whole mask. When moulding the shield on to the plaster cast the softened tablet is first folded back over the nasion so that the bridge is strengthened by a double thickness of material. The eye apertures (each about the size of a shilling) are next formed by incising the wax over the ocular prominences, and the material is then pulled out and worked into the required form. The cast and wax are immersed in a basin of hot water during the manipulations. A little practice soon enables one to make a satisfactory mask; but care must be taken to avoid over-heating the wax and making it too brittle in consequence.

Special attention should be paid to making a close fit at the upper nasal angle of each orbit so that any tendency of the shield to slip upwards when in use may be resisted.

Messrs. Clement Clarke supply a shield made on these lines. They employ a non-inflammable material which resembles celluloid and is considerably stronger and lighter than dental wax. This fulfils the purpose admirably and seldom requires to be moulded to the individual, since, though sufficiently rigid to afford protection, it is elastic enough to allow adaptation to almost any patient. I am much obliged to Mr. H. C. Binstead for the trouble he has taken in obtaining this material which is superior to dental wax in many respects. Masks made of it are very comfortable to wear and are not difficult to mould, though a rather higher temperature is necessary than that required by the wax. 